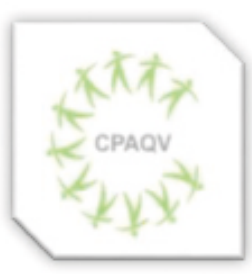

ISSN: 2178-7514

Vol. 12| No. 1| Ano 2020
ARTIGO ORIGINAL

\section{FUTEBOL AMERICANO: DESENVOLVIMENTO DA MODALIDADE FLAG NA CIDADE DE MOGI GUAÇU}

\section{American soccer: development of flag modality in Mogi Guaçu}

\author{
Marcelo Francisco Rodrigues ${ }^{1}$, André Luís Machado Mariano², \\ Francisco Arruda Mello Junior ${ }^{2}$, Kleber Aparecido Borges Pedroso, Henrique Miguel ${ }^{3}$
}

\title{
RESUMO
}

Introdução: Considerando que esportes não tradicionais, como o futebol americano, tem apresentado um crescimento considerável no Brasil, fez-se necessário a pesquisa para avaliar se a evolução da modalidade é a mesma na cidade de Mogi Guaçu. Objetivo: Pesquisar o desenvolvimento do futebol americano na cidade de Mogi-Guaçu. Método: Foi realizada uma pesquisa de campo de caráter qualitativo, com uma equipe que representa a cidade. Resultados: A modalidade pode ser praticada de várias formas e com objetivos diferentes por seus praticantes, apresentando-se de maneira recreativa ou de lazer, na forma de iniciação esportiva ou até mesmo como uma simples prática alternativa. Nota-se que esportes não tradicionais, levam consigo uma variedade de vivencias, sendo elas de caráter corporal e cultural, pois em sua composição está a manifestação e tradição de outro país. Conclusão: Com o estudo podemos concluir que as pessoas procuraram o Futebol Americano como uma forma de recreação e lazer, pois não se sentiam motivados e confortáveis a praticar os esportes tradicionais oferecidos pela cidade.

Palavras-chave: Futebol Americano; Crescimento; Desenvolvimento.

\section{ABSTRACT}

Introduction: Considering that non-traditional sports, such as American football, have shown considerable growth in Brazil, research was necessary to assess whether the evolution of the sport is the same in the city of Mogi Guaçu. Objective: Research the development of American football in the city of Mogi-Guaçu. Method: A qualitative field research was carried out, with a team that represents the city. Results: The sport can be practiced in different ways and with different objectives by its practitioners, presenting itself in a recreational or leisure way, in the form of sports initiation or even as a simple alternative practice. It is noted that non-traditional sports take with them a variety of experiences, being of corporal and cultural character, because in its composition is the manifestation and tradition of another country. Conclusion: With the study we can conclude that people sought American Football as a form of recreation and leisure, as they did not feel motivated and comfortable to practice the traditional sports offered by the city.

Keywords: American Football; Growth; Development.

Autor de correspondência

Marcelo Francisco Rodrigues

UNIMOGI: Avenida Padre Jaime, 2.600.

Jardim Serra Dourada, Mogi Guaçu/SP.

Tel (19) 3831- 3080.

Email: marcelo.edufisica@hotmail.com
1)Professor na Faculdade Mogiana do Estado de São Paulo/FMG

2)Estudante de Educação física/Faculdade Mogiana do Estado de São Paulo/FMG

3)Discente dos cursos de Educação Física -UNIPINHAL- Espírito Santo do Pinhal/SP

DOI: $10.36692 / c p a q v-v 12 n 1-14$ 
Futebol americano: desenvolvimento da modalidade flag na cidade de Mogi Guaçu

\section{INTRODUÇÃO}

Hoje em dia, a procura por diversos e diferentes tipos de atividades físicas tem aumentado entre as pessoas. A preocupação com a saúde e qualidade de vida tem despertado o interesse da população na prática por esportes, tanto os convencionais como, futebol, basquete entre outros, como o Futebol Americano que é um esporte alternativo, mas que vem aumentando o número de praticantes. Matos ${ }^{(1)}$ nos sugere que esportes alternativos levam consigo algumas características como: possuir pouca visibilidade necessita de materiais especializados e diferenciados e não possuem contextualização sociocultural. Fermino e Fermino (2) sustentam que esportes alternativos são esportes não tradicionais, pouco populares ou jogos não investigados na aérea profissional e de mídia. Nesse estudo procuramos entender que além do futebol americano se apresentar como uma nova modalidade esportiva, ele também pode ser praticado, buscando os mais diversos objetivos, podendo ser pela finalidade esportiva, como uma pratica corporal alternativa ou até mesmo pela satisfação pessoal nos momentos de lazer.

Lorenzetto e Mattiense (3), afirmam que a procura por práticas corporais alternativas acontece com o intuito de diversão e não como fins esportivos. Andrade et al. ${ }^{(4)}$, apresentam a informação de que, as práticas corporais alternativas visam a integração do corpo e mente. Ainda no levantamento de dados identificamos que o futebol americano pode ser utilizado como ferramenta pedagógica no âmbito escolar ${ }^{(5)}$.

Entendemos que o lazer é um tempo no qual as pessoas podem ou não realizar algum tipo de atividade, sem a obrigatoriedade da ação. Bramante ${ }^{(6)}$ cita que lazer é um momento onde o indivíduo encontra-se livre, podendo realizar qualquer atividade que lhe proporcione satisfação pessoal. Além do lazer citado acima a prática do futebol americano acontece pelo fato do esporte ser enquadrado como uma atividade corporal alternativa.

Diante das informações encontradas, buscou-se entender a origem do esporte e como aconteceu o seu desenvolvimento em Mogi Guaçu.

O futebol americano é um esporte de origem norte-americana que possui em sua identidade a existência do contato físico, conquista de território e o jogo coletivo, segundo a literatura foi originado a partir de outro esporte mais antigo, o rugby. Ainda por intermédio do rugby, o Futebol Americano sofreu alterações até o seu formato atual, porém mantendo suas características ${ }^{(7)}$ Atualmente o futebol americano possui duas vertentes, o full pad e o flag, sendo que primeiro se caracteriza por utilizar os equipamentos de proteção e os contatos físicos são inevitáveis ${ }^{(8)}$. Já no flag, não é utilizado os equipamentos de proteção, os jogadores utilizam duas fitas, uma em cada lado da cintura, onde o adversário para interromper a jogada deve retirar uma das fitas ${ }^{(9)}$. 
Em relação ao crescimento da prática do futebol americano no mundo e principalmente na cidade de Mogi Guaçu, considera-se que pode ser devido aos veículos de comunicação que transmitem seu principal campeonato a NFL (National Football League). A transmissão dos jogos pelo mundo abrange 160 países, atingindo os continentes da Ásia, Europa e América do Sul. Isso levou ao aumento da popularidade do futebol americano inclusive no Brasil, contudo não existe um número exato de equipes de futebol americano no país.

A Confederação Brasileira de Futebol Americano (CBFA) é quem realiza o levantamento de dados em suas pesquisas, para avaliar o crescimento do esporte, porém CBFA constata que não são todas as equipes que estão registradas no órgão, pois optam pela consolidação do esporte antes de firmarem registro nas federações. O órgão responsável informam que deve existir no país mais de cem equipes espalhadas pelo território nacional. Dados revelam um aumento considerável no número de fãs em janeiro de 2016 em comparação a setembro de 2015 e o acesso à TV por assinatura é um fator contribuinte para o desenvolvimento da modalidade no país, além de promover o entendimento e conhecimento sobre as particularidades que o esporte possui ${ }^{(7)}$.

Apesar de termos várias informações disponíveis em sites esportivos e revistas do gênero, quando se trata de pesquisas acadêmicas ou cientificas, encontramos poucos registros sobre a modalidade. Ainda Costa et al ${ }^{(7)}$, afirmam que, as informações sobre o desenvolvimento do futebol americano no Brasil ainda são mínimas.

Diante do exposto, justifica-se o levantamento de dados em uma pesquisa de caráter qualitativo, para equipararmos os fatores que contribuem para o desenvolvimento do esporte e identificar quais são os fatores que causam interesse pela prática do futebol americano na cidade de Mogi Guaçu.

\section{REFERÊNCIAL TEÓRICO}

Apresentaremos a seguir, uma breve pesquisa, contextualizando a pesquisa a fim de justificar a mesma.

\section{HISTÓRIA DO ESPORTE}

O futebol americano, teve seu surgimento derivado de um outro esporte já conhecido que o precedeu, o Rugby de origem inglesa. Através do Rugby, o futebol americano sofreu várias alterações ao longo dos tempos, porém, não perdeu a característica de ser um jogo, coletivo, de conquista de território e contato físico. Segundo Duarte $^{(12)}$, sua popularização nos Estados Unidos (USA), está ligado ao futebol universitário, onde encontrou na rivalidade entre as universidades, o fator que precisava para se firmar. Em 1867, aconteceu a primeira fase de três partidas de futebol americano entre as equipes universitárias, de Yale e Harvard. 
Futebol americano: desenvolvimento da modalidade flag na cidade de Mogi Guaçu

\section{FUTEBOL AMERICANO FULL} PAD E FLAG

O full pad é a modalidade onde os atletas utilizam todos os equipamentos necessários para que o jogo aconteça em seu modo tradicional, sem adaptações, dentre os materiais utilizados estão capacetes, ombreiras, luvas e protetor bucal, tudo para preservar a integridade física dos $\operatorname{atletas}^{(8)}$. Já na modalidade flag, teve sua criação, como objetivo de ser um jogo pré desportivo, utilizado na iniciação do Futebol Americano possui adaptações em suas regras para evitar o contato físico mais forte, utilizando uma fita de cada lado da cintura de cada atleta. Os equipamentos de segurança não são utilizados no flag e para interromper a jogada é necessário que o atleta do time adversário retire uma das fitas amarradas na cintura do outro atleta, porém para a retirada da fita faz-se que o atleta adversário esteja com a posse de bola. Com isso o contato físico entre os jogadores é menor durante a partida ${ }^{(9)}$.

O Futebol Americano em suas duas variações tem como objetivo o avanço de território com a posse de bola. Cada time possui quatro tentativas para avançar 10 jardas, tentando chegar na end zone, local que acontece a pontuação, acontecendo quando o jogador passa com a bola em seu controle, fazendo um touchdown, a pontuação máxima do esporte ${ }^{(8)}$.

As equipes de Futebol Americano full pad e flag, em seu esquema tático, são compostas por três times, ataque, defesa e especialistas. Durante o jogo existe o momento certo para cada time estar em campo, quando a equipe $(\mathrm{X})$ está com a posse de bola fica o time de ataque e a outra equipe fica em campo com o time de defesa, já os especialistas entram somente nos momentos específicos, field goal e extra point ${ }^{(13)}$.

Após o touchdown acontece uns dos momentos chamados de extra point, a equipe que pontuou tem direito ao chute livre, podendo aumentar a pontuação da mesmo em um ponto, outro momento de chute é quando a equipe não consegue avançar as 10 jardas em quatro tentativas, nesse momento realiza um chute chamado de field goal que vale três pontos os chutes precisam passar por dentro do "Y" que são as traves usadas no Futebol Americano ${ }^{(13)}$.

\section{CHEGADA AO BRASIL}

De acordo com a literatura, o início da modalidade no Brasil está relacionado com a participação de norte-americanos na inserção do esporte dentro do pais. Segundo Rodrigues et al. (13), o início da prática deu-se através de grupos de amigos Brasileiros, apenas por diversão e por considerar o esporte interessante.

Ainda em nossa busca por mais informações sobre a chegada do Futebol Americano no Brasil, constatamos a participação da mídia brasileira na divulgação de esporte no pais, segundo Pons ${ }^{(14)}$ no ano de 1968 a rede de televisão, na época conhecida como TV TUPI, recebeu fitas de vídeo de alguns jogos da liga nacional de futebol americano, conhecida como 
NFL, os vídeos foram enviados pela rede norteamericana de televisão CBS. Segundo Souza et

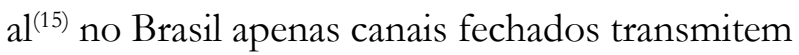
os jogos de Futebol Americano, devido a isso o esporte vem ganhando mais visibilidade e mais adeptos, dados indicam um aumento de $800 \%$ de telespectadores nos últimos anos.

\section{$\begin{array}{lll}\text { LAZER ESPORTE } & \text { E }\end{array}$}

\section{ALTERNATIVO}

Nos tempos livres o esporte da bola oval passou a ser praticado como forma de divertimento nos momentos de lazer. Segundo Bramante ${ }^{(6)}$, o lazer é uma experiência humana usada nos momentos de tranquilidade, podendo ser realizadas através de conquistas de bens materiais ou socializadas entre pessoas, gerando um momento de prazer e satisfação pessoal. Podemos entender que o início de um novo esporte pode acontecer em momentos de descontração. Segundo Gomes ${ }^{(16)}$ jogos e práticas corporais estão atreladas ao significado de lazer.

O Futebol Americano, assim como outros esportes não tradicionais como, Beisebol, Golfe, pode se tornar uma prática recreativa, segundo Marcelino ${ }^{(17)}$, as atividades recreativas emergem no sentido de ocupação do tempo, fora ocupação laboral e que seja de livre escolha, abarcando os anseios de divertimento e sensações de prazer advindo da prática que foi escolhida.

Com o passar dos anos a procura pelas práticas corporais alternativas tem aumentado na área da educação física. As pessoas começaram a utilizar essas práticas não como fins competitivos, mas sim pelo lazer e diversão causados por elas ${ }^{(3)}$.

Alguns estudos informam a importância dos esportes alternativos, segundo Pereira ${ }^{(18)}$ esportes alternativos são esportes de outras culturas, outros países ou até mesmo existentes no Brasil, mas que por questões culturais e midiáticas, a população acaba não tendo o conhecimento suficiente das suas origens, contexto histórico, sociais e culturais, e nem mesmo os benefícios que o esporte alternativo pode trazer para o indivíduo num todo. Segundo Godoy ${ }^{(19)}$, os benefícios proporcionados pela prática de esportes alternativos são muitos, tais como, melhoria do bem-estar pessoal, autoestima, autoconhecimento e aumenta o vigor e capacidades físicas.

Os esportes alternativos também podem influenciar os professores de Educação Física na forma de abordar os esportes não tradicionais tanto no âmbito escolar ou fora da escola. Segundo Baia et al. ${ }^{(20)}$, notou-se que possibilitando a prática de esportes não tradicionais no nosso país, podemos aumentar o leque de práticas corporais nas aulas de Educação Física, pois a mesma reduzida aos esportes convencionais não contribui para o entendimento do fenômeno esportivo participante de nossas vidas, além de não enriquecer a cultura corporal.

Diante do exposto, o Futebol Americano tem sido praticado e impulsionado por se apresentar como um esporte alternativo, vivenciado na forma de lazer e recreação. 
Futebol americano: desenvolvimento da modalidade flag na cidade de Mogi Guaçu

\section{MÉTODOS}

Para realização desta pesquisa, utilizouse o método etnográfico de pesquisa, sendo de caráter qualitativo, através de uma análise descritiva de questionário.

Segundo Barbosa ${ }^{(10)}$ a etnografia em seu entendimento é mais que um método, implica uma forma de fazer pesquisa tendo posturas teóricas, éticas e estéticas, possibilitando o condicionamento do trabalho de campo. Godoy ${ }^{(11)}$ informa que a pesquisa qualitativa possui grande credibilidade e através dela existe a possibilidade de estudar e compreender os fenômenos que envolvem a sociedade e seus ambientes diversificados. O pesquisador vai a campo coletar os dados dos sujeitos envolvidos, anotando todos os pontos de vista relevante a pesquisa, após isso analisa todos os dados para entender os fatores que levaram a tais respostas. Foi realizada também uma breve revisão de literatura acerca das relações pertinentes à pesquisa, como introdução mais ampla do tema bem como, bojo teórico para as discussões existentes na pesquisa.

As informações referentes aos fatores que acarretam o desenvolvimento do futebol americano na cidade de Mogi Guaçu foram coletadas através de uma pesquisa de campo com uma equipe de Futebol Americano modalidade flag, realizada no local de treinamento do time. A pesquisa contou a participação de 14 atletas amadores, homens, com a idade média de 23,6 $\pm 1,78$, que aceitaram responder as perguntas. $\mathrm{O}$ processo metodológico para a pesquisa de campo teve a realização através de um questionário elaborado pelos autores e impresso contendo oito perguntas pessoais, e sendo respondidas individualmente.

Os resultados encontrados foram apresentados em forma de gráfico, onde serão equiparados com pesquisa da mesma natureza metodológica, aplicado do questionário.

Referente aos atletas, os mesmos assinaram um termo de consentimento livre e esclarecido antes de responderem as questões, sanando todas as dúvidas dos participantes.

Os critérios de inclusão foram: os participantes teriam de estar escritos no time e sentirem interessados e confortáveis em responder o questionário proposto. Já o critério de exclusão apresenta-se, a partir do momento que os praticantes não se sentirem confortáveis com a pesquisa ou por qualquer risco que apresente a falha de sigilo com seus dados. Esta pesquisa foi aprovada pelo comitê interno de pesquisa UNIMOGI com o número de protocolo 201905.

\section{RESULTADOS E DISCUSSÃO}

A seguir, apresentam-se os gráficos com dados obtidos a partir das respostas do questionário proposto aos atletas, analisando e comparando com os trabalhos encontrados na literatura especifica do tema.

A primeira questão referente a esta pesquisa será demonstrada na figura 1 abaixo tendo como questionamento, a forma como conheceram o Futebol Americano. 


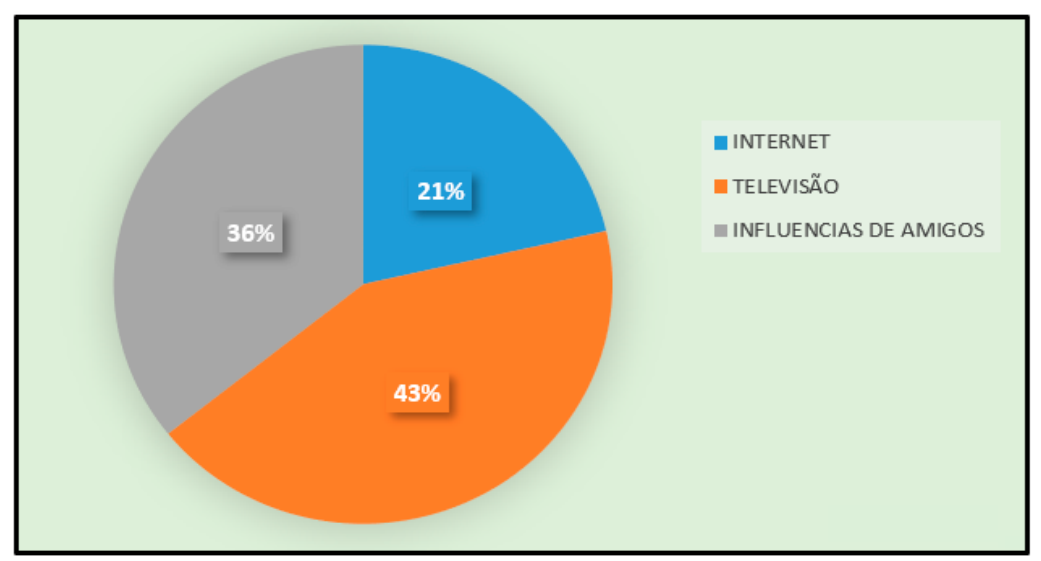

Figura 1: Como conheceu o Futebol Americano?

Pela seguinte questão abordada na Santaella, ${ }^{(21)}$ cita a televisão como mecanismo pesquisa e demostrada na figura 1, buscando midiático mais importante e impactante no identificar como os atletas conheceram o futebol Brasil, pelo seu poder de alcance popular. Assim americano, obtendo como respostas que 43\% observamosqueasmaiorias dosatletasconheceram foram pela televisão, $36 \%$ influencias de amigos e $\quad$ o futebol americano através da televisão. $21 \%$ internet. Segundo Souza et al. ${ }^{(15)}$, nos últimos anos ouve um aumento de $800 \%$ na audiência ao tempo de prática do futebol americano. do futebol americano na televisão Brasileira, mesmo sendo transmitidos em canais fechados.

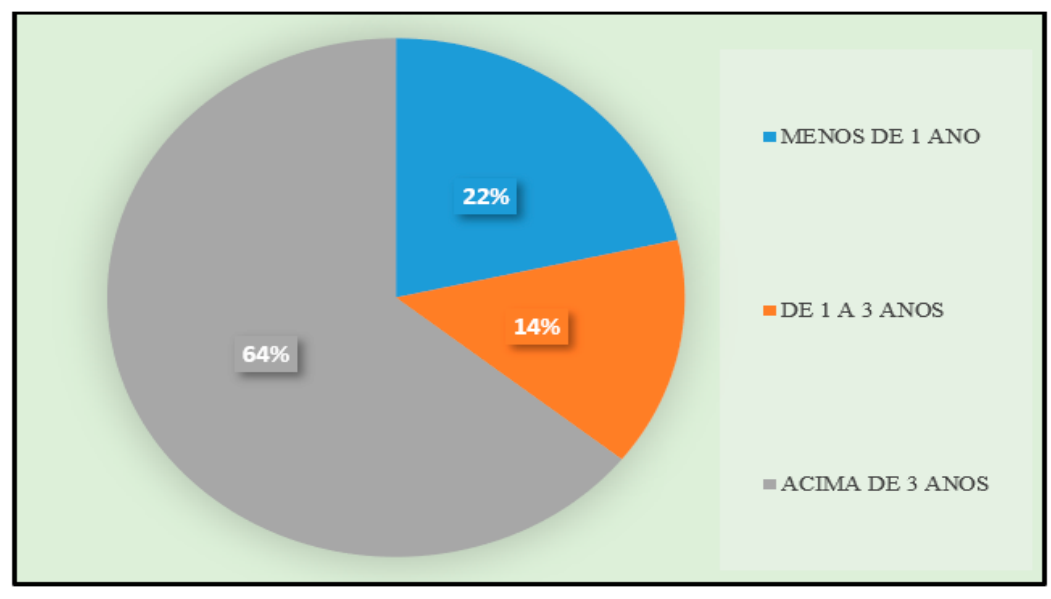

Figura 2: Há quanto tempo prática o Futebol Americano? 
Pela questão abordada na figura 2 infância, o atleta pode ficar de seis a dez anos na buscando identificar, a quanto tempo os atletas estão praticando o futebol americano, assim obtivemos as seguintes repostas. Dentre todos os atletas, 64\% praticam acima de 3 anos, 22\% menos de 1 ano e 14\% entre 1 a 3 anos. Segundo Massa et al ${ }^{(22)}$, o tempo de prática de cada atleta, leva em conta a base esportiva que cada um teve na sua infância como desenvolvimento motor e modalidade praticada durante adulto. Com isso constatamos que a maioria dos atletas envolvidos em nossa pesquisa demonstra ter contato com alguma base de formação esportiva, pois praticam o futebol americano a mais de 3 anos.

A seguir apresentaremos a figura 3, questionando à idade em que os atletas iniciaram a prática do futebol americano. Smith ${ }^{(23)}$ diz que após essa iniciação esportiva na

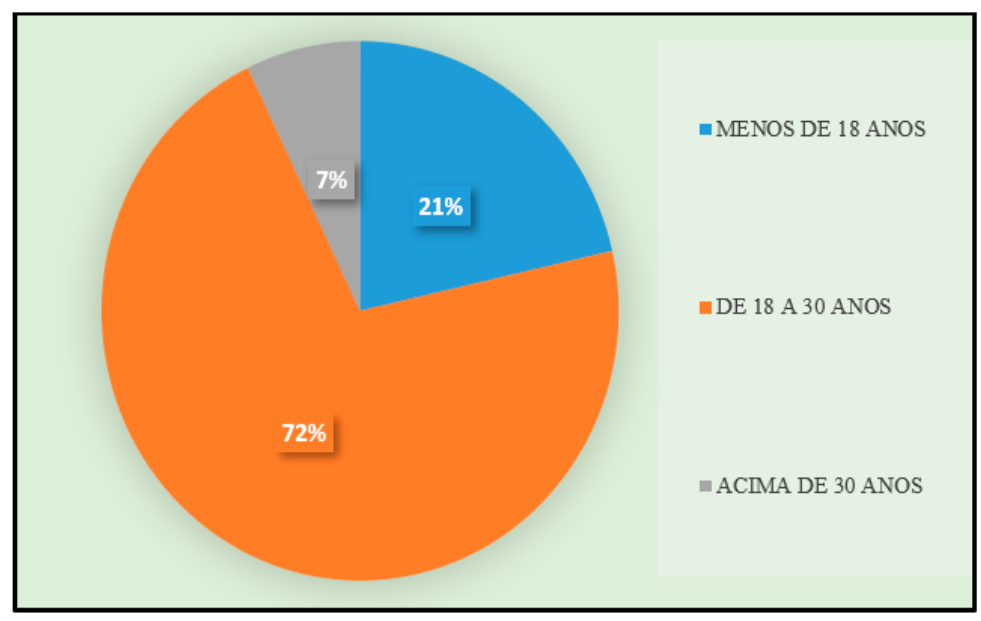

Figura 3: Com quantos anos começou a jogar Futebol Americano?

Procurando identificar qual a média de idade, que os atletas iniciaram a pratica do futebol americano, como apresentado na figura 3 , onde encontramos que $72 \%$ dos atletas começaram entre 18 a 30 anos, 21\% menores de 18 anos e 7\% acima de 30 anos. Segundo Silva ${ }^{(24)}$, muitas pessoas no Brasil, apresentam dificuldades para começar a praticar novos esportes na fase adulta, dificultados pela falta de orientação esportiva para pessoas adultas e principalmente pela falta de grupos específicos de iniciação tardia.

Pimentel et al ${ }^{(25)}$, acrescentam que, jovens adultos podem iniciar a prática esportiva buscando uma melhora na qualidade de vida ou pela busca de novos desafios, saindo de sua rotina. Diante desses estudos notamos que, as pessoas buscam praticar modalidades esportivas na idade adulta, para aliviar o estresse acumulado durante os dias e também para a melhora da saúde e quando acham esse ponto de equilíbrio entre vida e esportes acabam ficando um bom tempo na modalidade escolhida.

A seguir apresentado na figura 4, onde obteve os resultados sobre a questão referente aos fatores contribuintes para o início da prática da modalidade. 


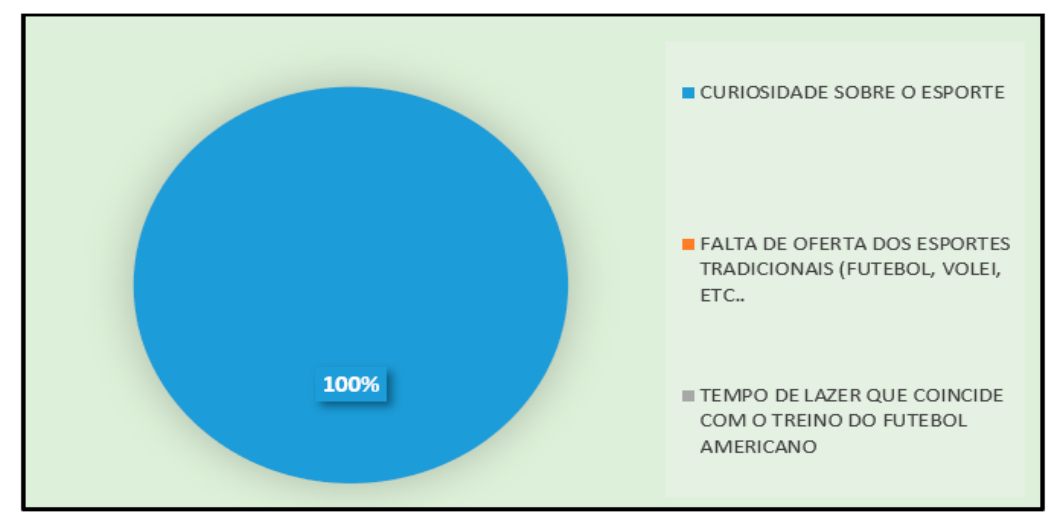

Figura 4: Quais os fatores que podem contribuir para que novas

pessoas iniciem a prática do Futebol Americano?

Figura 4: Quais os fatores que sem pensar em competições e Pons ${ }^{(14)}$ diz que podem contribuir para que novas pessoas dirigentes de times já profissionalizados, afirmam iniciem a prática do Futebol Americano? que o futebol americano começou a ser praticado

Nesta pesquisa, buscou-se identificar porgrupos de amigos, apenas por diversão. Diante os fatores que incentivaram os indivíduos a disso comparando com os dois autores, vimos iniciarem a prática de um esporte não tradicional, que a prática esportiva começou sem o intuito de o futebol americano, como mostra a figura 4. participar de competições e sim pela curiosidade Observando que $100 \%$ dos atletas iniciaram de aprender e vivenciar o futebol americano. a prática da modalidade pela curiosidade. E Abaixo na figura 5, referente segundo Rodrigues et al. ${ }^{(13)}$ a prática do futebol aos primeiros contatos com o Futebol americano, começou a ser praticada por grupos de Americano, buscando identificar por qual amigos, apenas para conhecer o esporte, no início premissa deu-se a prática inicial do esporte.

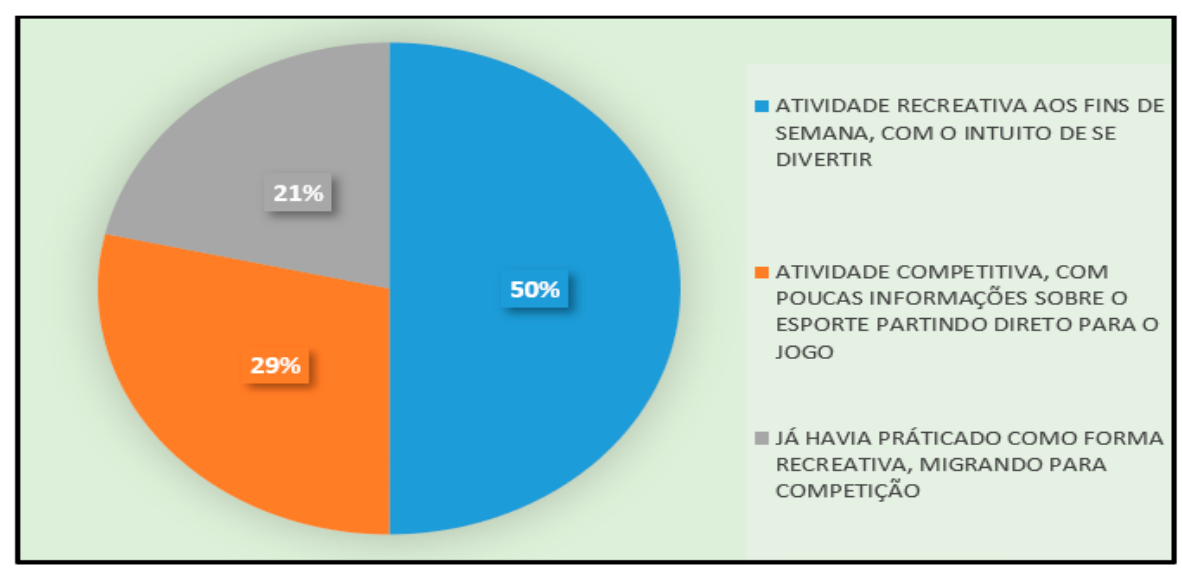

Figura 5: Por qual premissa aconteceu o início da pratica do Futebol

Americano? 
Entendendo com esta questão, o que os motivou à jogar o Futebol Americano, como mostra o gráfico $5,50 \%$ dos jogadores começaram pelo fato de ser uma atividade recreativa e aos fins de semana, $29 \%$ por ser uma atividade competitiva e $21 \%$ já havia praticado como forma de competição. Segundo Lorenzetto e Matthiesen ${ }^{(3)}$, as pessoas começam a utilizar essas práticas não pela competitividade, mas sim pelo momento de diversão causado por elas e Gomes ${ }^{(16)}$, cita que jogos e práticas corporais estão atrelados ao significado de lazer, incorporando a conectividade entre corpo e mente. Através disso, constatamos que a prática inicial da modalidade aconteceu através de um caráter recreativo, sem fins competitivos, buscando simplesmente o lazer e bem estar. A seguir na figura 6, apresentaremos as opiniões dos atletas de Futebol Americano, sobre os contatos físicos que existe na modalidade.

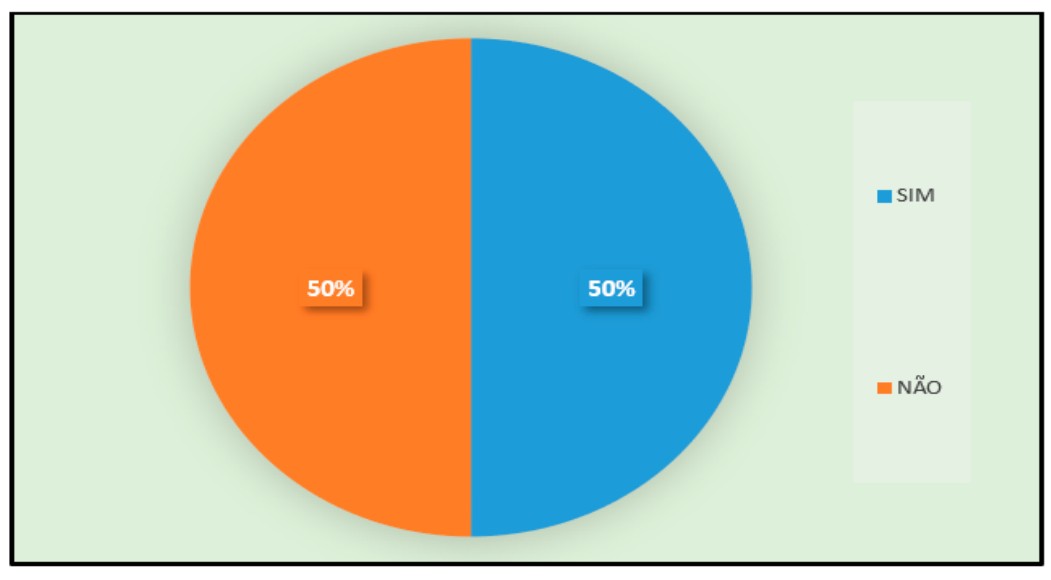

Figura 6: sabendo-se que é um esporte com muito contato físico, isso

foi determinante para escolha da modalidade?

Sabendo-se que o contato físico dentro do Futebol Americano é predominante, identificou-se esse fator que interferiu na escolha da modalidade. Referente ao assunto elaborando uma questão apresentada na figura 6, onde obtivemos os seguintes resultados, $50 \%$ dos atletas, afirmaram que sim, o contato físico foi um fator que motivou o início pela prática do esporte, e os outros $50 \%$ afirmaram que o fato de existir o contato físico causou uma reflexão negativa, referente a escolha pela modalidade. Segundo Andreasen e Andreasen (26), afirmam que as lesões dependem realmente do esporte que será praticado, principalmente esporte com muito contato físico, as lesões podem ser um fator que proporciona a dúvida de novas pessoas que querer iniciar a prática desses esportes.
Ainda Sane e Ylipaavalniemi ${ }^{(27)}$, informam que as lesões mais causadas por esses esportes são as lesões orofaciais referente a boca e face, ocasionados devido à velocidade e força do impacto na hora do contato físico. Como no futebol americano, os seus contatos acontecem com os jogadores em alta velocidade as lesões podem ser mais graveis, mesmo diante dos riscos, os atletas começaram a praticar o esporte, levando em conta que a modalidade praticada por eles é o Futebol Americano flag, apresentando menos contatos físicos em comparação à modalidade full pad, onde o contato é inevitável. A seguir, na figura7, questionamos os atletas, se existiu algum contato com esportes não tradicionais na época escolar ou no período de infância. 


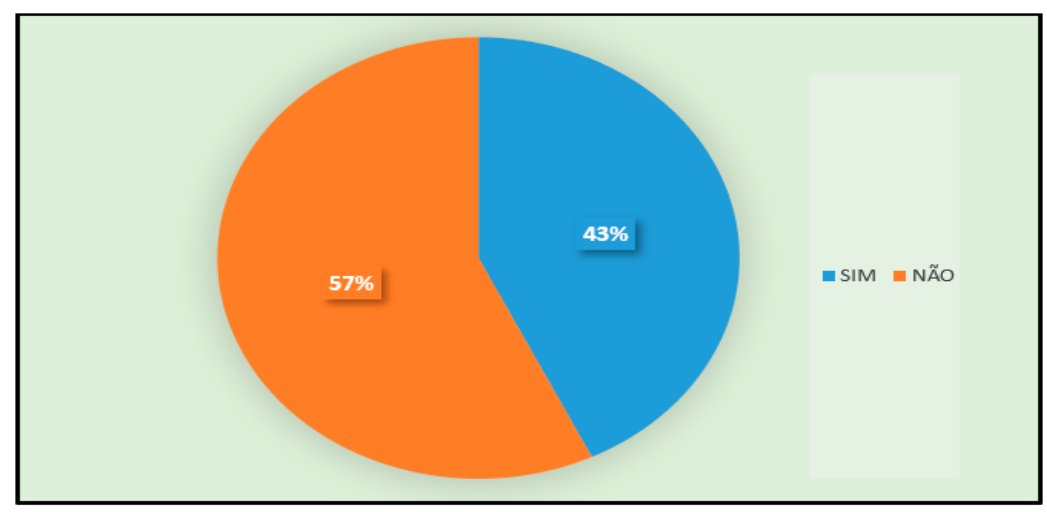

Figura 7: Na infância teve algum contato com esportes não

convencionais?

A vivencia esportiva não é proporcionada somente em clubes, as escolas também oferecem o convívio com as modalidades esportivas. Com isso buscou-se identificar se houve contato com algum esporte não tradicional na época escolar e no período de infância, Assim obteve na figura 7, o resultado de $57 \%$ dos participantes nunca haviam visto outros esportes fora os tradicionais do nosso país e 43\% já tiveram contato com algum esporte não tradicional do nosso país. Segundo Oliveira e Albuquerque ${ }^{(28)}$, a importância de apresentar novos esportes em ambientes escolares, proporciona benefícios na vida dos alunos, tanto no âmbito físico e mentalmente.
Ainda Finck (29), cita que podemos aumentar o número de praticantes e/ou espectadores de novas modalidades, colaborando na divulgação de novos esportes. Através desta resposta, percebemos qual a importância de conhecer novas práticas corporais e novas modalidades esportivas durante a infância, o que proporciona novos admiradores e jogadores da modalidade, apresentando um leque maior de ofertas de esportes que podem ser praticado por crianças no Brasil. A figura 8 abaixo trata da última questão abordada neste trabalho, querendo saber, dos fatores que podem ajudar a divulgar o Futebol Americano no nosso pais.

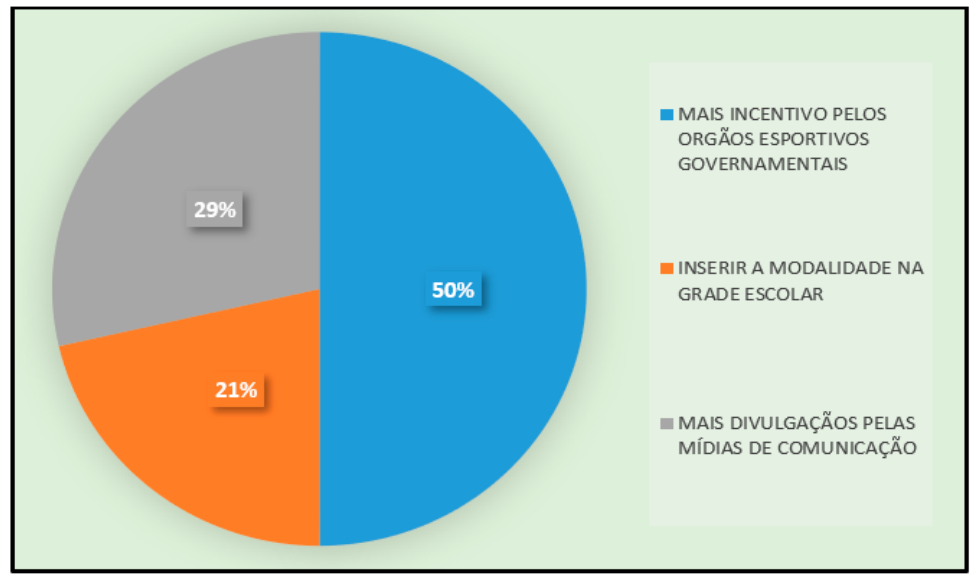

Figura 8: Quais os fatores que podem contribuir para o 
Futebol americano: desenvolvimento da modalidade flag na cidade de Mogi Guaçu

Devido ao crescimento do futebol americano no Brasil, buscando entender quais os fatores que podem contribuir para o desenvolvimento da modalidade no país, como apresentado na figura 8, observou que 50\% dos atletas indicaram mais incentivos de órgãos esportivos governamentais, $21 \%$ optaram pela inserção da modalidade na grade escolar e $29 \%$ votaram na divulgação do esporte pelas mídias de comunicação. Segundo Isayama et $\mathrm{al}^{(30)}$, pela falta de financiamento no esporte e falta de recursos, a impressão que se tem, é de má gestão e má distribuição do dinheiro pelos estados e municípios, assim dificultando o desenvolvimento do esporte na cidades e no país. Mezzadri et $\mathrm{l}^{(31)}$, informam que o financiamento político ao esporte, se resume apenas em esportes de alto rendimento e não na iniciação, pois o auto rendimento causa retorno financeiro maior. Diante das informações, comprovamos que a falta de apoio pelos órgãos governamentais é real, sendo assim o desenvolvimento de qualquer modalidade sem apoio, coloca em atraso a evolução do esporte, consequentemente acarreta o impedimento de outros indivíduos em desfrutar dos benefícios proporcionados pela modalidade. Ainda entendemos que, mesmo com o pouco apoio à destinação correta da verba, englobando todos os anseios esportivos e não priorizando somente um, no caso o alto rendimento, podendo também ajudar na divulgação via propaganda na televisão, que é o maior meio de comunicação do nosso país.

\section{CONCLUSÃO}

O Futebol Americano é um esporte popular nos Estados Unidos, que vem apresentando um grande crescimento de espectadores e praticantes da modalidade ao redor do mundo. Mas por não ser um esporte popular em outros países ele se apresenta como um esporte alternativo, é como acontece no Brasil. Nesse estudo buscamos coletar dados referentes a quais os fatores que influenciam no desenvolvimento do futebol americano na cidade de Mogi Guaçu.

Com o estudo podemos concluir que as pessoas procuraram o Futebol Americano como uma forma de recreação e lazer, pois não se sentiam motivados e confortáveis a praticar os esportes tradicionais oferecidos pela cidade, devido a isso concluímos que a falta de incentivo pelos órgãos governamentais, utilizando a verba financeira somente para esportes de alto nível que ao mesmo tempo são os esportes tradicionais do nosso país, e deixando de lado o investimento em iniciação esportiva de novas modalidades, pois notou-se que a grande maioria dos atletas iniciaram a prática já na fase adulta, de forma tardia, pois se encontravam com a formação física e mental já desenvolvida para escolher o Futebol Americano como esporte a ser jogado. Diante das informações encontradas e aplicadas neste estudo, notamos que os meios de comunicação se apresentaram como um fator importante para o desenvolvimento e conhecimento da modalidade, até porque os atletas entrevistados afirmaram em 
Futebol americano: desenvolvimento da modalidade flag na cidade de Mogi Guaçu

sua grande maioria conhecer o esporte através de canais específicos sobre esporte.

Concluindo que o futebol americano é um esporte novo e vem crescendo rapidamente no Brasil e na cidade de Mogi Guaçu, possuindo no pais mais de cem equipes participando de torneios amadores e profissionais, mesmo sendo pouco estruturado, pois o esporte não tem uma grande visibilidade no mercado midiático no nosso pais, afetando assim futuros investidores que queiram patrocinar o futebol americano.

Sabemos que são poucos os estudos relacionados ao desenvolvimento de esportes não tradicionais em nosso país, por esse motivo faz-se necessário analisar e desenvolver mais pesquisas relacionadas ao tema, pois assim poderemos contribuir com o desenvolvimento de novas modalidades.

\section{REFERÊNCIAS}

1. Matos M. Esportes Alternativos: o que são e quais são seus benefícios para a Educação Física Escolar? Revista Saúde Física \& Mental-ISSN 23171790, 6.2: 1-11. 2018.

2. Fermino PHD, Fermino RS. A inclusão do tema esportes alternativos em aulas de Educação Física na rede pública de ensino do estado de São Paulo. In: Anais VII Seminário de Metodologia de Ensino da Educação Física. USP: 2018.

3. Lorenzetto LA, Matthiesen SQ. Práticas corporais alternativas. Rio de Janeiro: Guanabara Koogan, 2008.

4. Andrade MO, Bonfim EE, Guedes FLA. Práticas corporais, identidade e formação de habitus entre grupos de praticantes da capoeira e da dieta naturalística. Vivência: Revista de Antropologia, 1.51. 2018.

5. Abreu M, Silva C. Futebol americano: uma nova proposta na educação física escolar. Anais do EVINCI-UniBrasil, 3.1: 160-160. 2018.
6. Bramante AC. Lazer: concepções e significados. Licere, Belo Horizonte, v. 1, n. 1, p. 9-17, set. 1998.

7. Costa NCG, Bueno IA, Rodrigues FXF. O futebol americano numa perspectiva históricosociológica: o caso de mato grosso. Recorde: Revista de História do Esporte, 10.1. 2017.

8. Pinto SIF, Erdacki VS, Biesek S. Avaliação da perda hídrica e do grau de conhecimento em hidratação de atletas de futebol americano. Rev Bras Nut Esp.:8(45):171-9. 2014.

9. Perfeito R, Junior CASS, Nascimento CJJ, Ferreira F, et al. Apresentação do Flagfootball como possibilidade pedagógica. Revista Augustus. Rio de Janeiro, v.17, n.34, jul/2012.

10. Barbosa RB. Perspectivas e tradições do fazer etnográfico. Anuário Antropológico, Brasilia, UnB, v. 41, n. 2: 127-155, 2016.

11. Godoy AS. Pesquisa qualitativa: tipos fundamentais. Revista de Administração de empresas, v 26, 2, São Paulo, p20-29. jul/ago, 1995.

12. Duarte A. História dos esportes. 4. ed. São Paulo: Ed. SENAC, 2004.

13. Rodrigues FXF, Costa NCG, Pedroso LC, Silva JA. Futebol americano no país do futebol: o caso do cuiabá arsenal. Barbarói, Santa Cruz do Sul, n.41, p. $<227-247>$, jul./dez. 2014.

14. Pons RVS. Futebol americano no Brasil: um estudo com inspiração etnográfica sobre as práticas de consumo. 190 p. Dissertação (Mestrado em Administração) - Universidade Federal do Rio de Janeiro, Rio de Janeiro, 2013.

15. Souza VC, Silva RC, Picoli RMM. Motivação de atletas brasileiros de futebol americano. EFDeportes.com, Revista Digital. Buenos Aires, Año 20, No 211, Diciembre de 2015.

16. Gomes CL. Lazer: necessidade humana e dimensão da cultura. Revista Brasileira de Estudos do Lazer, Belo Horizonte, v. 1, n. 1, p. 3-19, jan./abr. 2014.

17. Marcellino NC. Lazer e educação. 9. ed., Campinas-SP, Papirus, 2002.

18. Pereira JM. A formação do bacharel em educação física e esporte: em contexto, as disciplinas de voleibol. Rio Claro: universidade estadual paulista, p. 24. 2004.

19. Godoy RFD. Benefícios do exercício físico sobre a área emocional. Movimento. ;8(2):7-16. 2002. 20. Baia AC, Machado RB, Bonifácio IM. Futebol americano e beisebol em aulas de educação física: experiências em debate. Iniciação \& Formação Docente, v. 2, n. 2, Uberaba, out. 2016.

21. Santaella LA. Cultura das mídias. São Paulo: Experimento, 1996. 
22. Massa M, Uezu R, Pacharoni R, Bohme MTS. Iniciação esportiva, tempo de prática e desenvolvimento de judocas olímpicos brasileiros. Rev. Bras. Ciên. Esporte, Florianópolis, v. 36, n. 2, p. 383-395, abril/junho, 2014.

23. Smith DJA. Framework for understanding the training process leading to elite performance. Sports Medicine, 33, 15, 1103-1126. 2003.

24. Silva RMP. Pedagogia do esporte: iniciação tardia em basquetebol. Monografia (Bacharelado em Educação Física) - Faculdade de Educação Física, Universidade Estadual de Campinas, Campinas, 2008. 25. Pimentel RM, Galatti LR, Paes RR. Pedagogia do esporte e iniciação esportiva tardia: perspectivas a partida da modalidade basquetebol. Pensar a Prática, Goiânia, v.13, n.1, p 1-15, jan./abr. 2010.

26. Andreasen JO, Andreasen FM. Texto e atlas colorido de traumatismo dental. Porto Alegre: Artmed Editora, 2001. Cap. 21.

27. Sane J, Ylipaavalniemi P. Dental trauma in contact team sports. Endod. Dent. Traumatol. v.4, n.4, p.164-169, 1988

28. Oliveira VD, Albuquerque LR. Esportes Complementares na Educação Física Escolar do Ensino Médio. In: X Congresso Nacional De Educação - Educere - I Seminário Internacional De Representações Sociais, Subjetividade E Educação Sirsse. Anais... Curitiba - PR: PUCPR, p. 5179 - 5191. 2011.

29. Finck SCM. A Educação Física e o esporte na escola: cotidiano, saberes e formação. Curitiba: Ibpex. 2010.

30. Isayama HF, Pinto LMSM, Uvinha RR, Stoppa EA. Lazer, políticas públicas e formação profissional: análise da política de formação profissional de secretarias de esporte de municípios da região metropolitana de Belo Horizonte. Gestão de políticas de esporte e lazer. Belo Horizonte: Ed. da UFMG, p.211-227, 2011.

31. Mezzadri FM, Martines IC, Starepravo FA. Apontamentos iniciais acerca das políticas públicas para o esporte e o lazer em municípios paranaenses. In: ISAYAMA, H. F. et al. Gestão de políticas de esporte e lazer. Belo Horizonte: Editora UFMG. 521p. p. 123-135. 2011.

OBSERVAÇÃO: Os autores declaram não existir conflitos de interesse de qualquer natureza. 